\title{
A metaphoric rhetorical criticism on Aminuddin Baki's speech: some preliminary findings
}

\begin{abstract}
The purpose of this paper is to look at the Aminuddin Bakiôs Torch Movement Speech (Ceramah Gerakan Obor) from the critical theory of metaphorical perspective. The study of metaphor is considered important because it has been used by many speech writers, authors, and CEOs in big organisations to strengthen the impact of their speeches. Metaphors are used to amplify meanings in oneôs speech. The objective of the study is to identify the type of metaphors employed and how the metaphors are conveyed within the Torch Movement Speeches. The study also hopes to identify the direction of metaphor used in terms of positive, negative or neutral which is predominant in the speech. Numerous studies have been done on the biographical portion of Aminuddin Baki but not of the particular speeches he had made on the progression of the natives in Malaysia as a whole. The late Aminuddin Baki was known as a man of great purpose and was committed to seeing the advancement of Malaysians in education. This study used a qualitative method through a rhetorical analysis of one of Aminuddin Bakiôs Torch Movement speech. Using Neo-Aristotelian Criticism perspective in the analysis of speech, this study demonstrates the relevance in the application of ancient Malay metaphor in modern day communication interaction among the people.
\end{abstract}

Keyword: Aminuddin Baki; Neo-Aristotelian; Metaphor; Rhetorical analysis; Speech 